\title{
A new hand assessment instrument for severely affected stroke patients
}

\author{
Doris Broetz $^{\mathrm{a}, *}$, Nicholas A. Del Grosso ${ }^{\mathrm{a}}$, Massimiliano Rea ${ }^{\mathrm{a}}$, Ander Ramos-Murguialday ${ }^{\mathrm{a}, \mathrm{b}}$, \\ Surjo R. Soekadar ${ }^{\mathrm{a}, \mathrm{c}}$ and Niels Birbaumer ${ }^{\mathrm{a}, \mathrm{d}}$ \\ ${ }^{a}$ Institute of Medical Psychology and Behavioral Neurobiology, MEG Center, University of Tuebingen, \\ Tuebingen, Germany \\ ${ }^{\mathrm{b}}$ Health Technologies Department, TECNALIA, San Sebastian, Spain \\ ${ }^{c}$ Department of Psychiatry and Psychotherapy, University of Tuebingen, Tuebingen, Germany \\ ${ }^{\mathrm{d}}$ Ospedale San Camillo, Istituto di Ricovero e Cura a Curattere Scientifico, IRCCS, Venezia, Italy
}

\begin{abstract}
.
BACKGROUND: Standard assessment instruments cannot differentiate patients with minimal residual hand function after stroke. As a result, changes in motor recovery are difficult to document using currently-available tests. In a controlled study with chronic stroke patients without residual finger extension, a new hand function test has been developed. This instrument, called Broetz Hand Test (BzH), allows to assess small variations in hand function in severely paralyzed stoke patients. The instrument is easy to use, and was developed using principles of motor learning and behavioral assessment.

METHODS: The instrument consists of seven daily life-oriented tasks, each of which asks for movement of the paralyzed hand. BzH of 20 patients after stroke was evaluated before and after a behavioral physiotherapy treatment. Sensitivity, inter-observer reliability, test-retest reliability and construct validity was calculated.

RESULTS: Two-tailed paired-samples $t$-test before and after treatment demonstrated sufficient sensitivity. Mean agreement between the raters resulted in an excellent interrater-reliability. Test-retest reliability between the pre- and post-treatment scores was 0.9 . The correlation between $\mathrm{BzH}$ and standard test scores was statistically significant and demonstrated sufficient validity. CONCLUSION: The BzH is a valid and reliable tool to assess changes in hand function in severely paralyzed patients after stroke.
\end{abstract}

Keywords: Stroke, assessment, hand function, physiotherapy, rehabilitation

\section{Introduction}

A test is needed that assesses small changes in the ICF (International Classification of Functioning, Disability and Health) components of functions and activities in severely paralyzed stroke patients, meaning that the patients are not able to extend the fingers actively and are not able to use the hand in daily life. They cannot grasp or release objects. Minor changes like releasing an object are not assessed with the available instruments.

\footnotetext{
*Address for correspondence: Doris Broetz, MEG Center, University of Tuebingen, Otfried-Mueller-Str. 47, 72076 Tuebingen, Germany. Tel.: +49 1631640558; E-mail: doris.broetz@web.de.
}

The Fugl-Meyer Test (FMA) (Fugl-Meyer et al., 1975 ) is the most frequently-used assessment instrument for chronic stroke patients and consists of 5 subscores: passive joint movement, pain during joint movements, sensibility, motor skills of upper arm and forearm and motor skills of hand and fingers. This test aims to measure functional recovery according to the ICF component of functions of the paralyzed arm.

Reliability of arm and hand function assessments like FMA (ICF component function), ARAT (Action Research Arm Test, ICF component activity) (Carroll, 1965) and Box and Block Test (BBT, ICF component activity) (Mathiowetz et al., 1985) for neurologically 
impaired patients with residual hand function has been demonstrated (Platz et al., 2005; Koski et al., 2007; Wei et al., 2011). Correlations between the scales measuring motor function is high, but correlation with measures of daily life impairment like the Hemispheric Stroke Scale (Adams et al., 1987) and the Modified Bartel Index (ICF component activity) (Shah et al., 1989) is moderate or insufficient (Platz et al., 2005). The outcome of the three arm motor tests (FMA, ARAT and BBT) is independent of the patient's ability to cope with activities of daily living as measured with the Modified Barthel Index.

The Nine-Hole Peg Test (NHPT, ICF component activity) (Sharpless, 1982) showed good test-retest and interobserver reliability (Heller et al., 1987) but only moderate correlations of NHPT, BBT and ARAT with the FMA and Motor Activity Log (MAL) have been achieved (Dromerick et al., 2006; Lin et al., 2010).

The Wolf-Motor-Function-Test (WMFT, Wolf et al., 2001; ICF component activity) is reliable and valid (Morris et al., 2001; Wolf et al., 2001) and has been developed for patients who are eligible for constraintinduced therapy, where active finger extension and grasping skills are required.

The above mentioned instruments require experience of the examiner and special equipment. The daily lifeoriented tasks (e.g. in the WMF) require intact hand and arm function.

Self-rating scales intended to evaluate the use of the affected hand in daily living like the MAL (ICF component activity) (Uswatte et al., 2005) often reflect the patients expectation and motivation more than the actual use of the paretic hand. The Stroke Impact Scale (Duncan et al., 1999) has been described as a valid instrument to evaluate the subjective attitude towards the consequences of stroke.

There is clear evidence for the reliability and validity of Goal Attainment Scaling (GAS) (Kiresuk and Sherman, 1968; Hurn et al., 2006). The structured GAS reflects changes in meaningful daily life skills (ICF component activity and function). But clinical experience of the examiner in identification of realistic goals, communication with the patient and extensive training of goal attainment scaling is needed.

The Broetz Hand Test has been developed with the following aims:

1. To evaluate small changes in upper limb motor function in severely paralyzed stroke patients.

2. To communicate realistic goals of using a severely paralyzed hand after stroke in daily living.

3. To require a minimum of equipment and technology.
4. To use only alternative judgments (present - not present) to minimize subjective bias of the examiner e.g. concerning the quality of the movement or the time consumed.

All tasks support an external focus of attention and allow feedback. The test observes the basic rules of motor learning and motivation as described by G. Wulf (Wulf et al., 2010).

\section{Procedure}

\subsection{Description of the instrument}

The instrument consists of seven daily life-oriented tasks that the patient is asked to perform in a standardized manner. The tasks demand different complex movements of the paralyzed hand, forearm and upper arm. The patient should always move the paralyzed hand. Compensation movements e.g. to touch the paralyzed hand with the non paralyzed hand, opening the fist or closing the fingers with the healthy hand are not permitted. The test aims to assess recovery in daily life functioning and at the same time to motivate the patient and the therapists to exercise and to use the daily life oriented actions of the $\mathrm{BzH}$ in daily life.

Each task can be performed in three different versions (words in bold mark those aspects of the task that change from one version to the other) e.g. (1) Patient pushes the newspaper into the paralyzed hand with the help of the non-paralyzed hand - holds it- carries it 5 meters while walking- grabs it from the paralyzed hand with the help of the non paralyzed hand - (2) Patient pushes the newspaper into the paralyzed hand with the help of the non paralyzed hand- holds it- carries it 5 meters - lays the newspaper on the table - (3). - Patient grasps the newspaper with the paretic hand, after using the healthy hand to bring it to a comfortable position for grasping - holds it - carries it 5 meters - lays the newspaper on the table.

The tasks are rated with (1) to (3) points. If the patient did not accomplish any version of the task, it is rated as zero. The tasks and each consecutive version of the tasks are of different difficulty levels.

See Supplement No 1 documentation sheet

\subsubsection{Test material}

1. Small-sized bolt: weight about $130 \mathrm{~g}, 8 \mathrm{~cm}$ length, $1,7 \mathrm{~cm}$ diameter. 


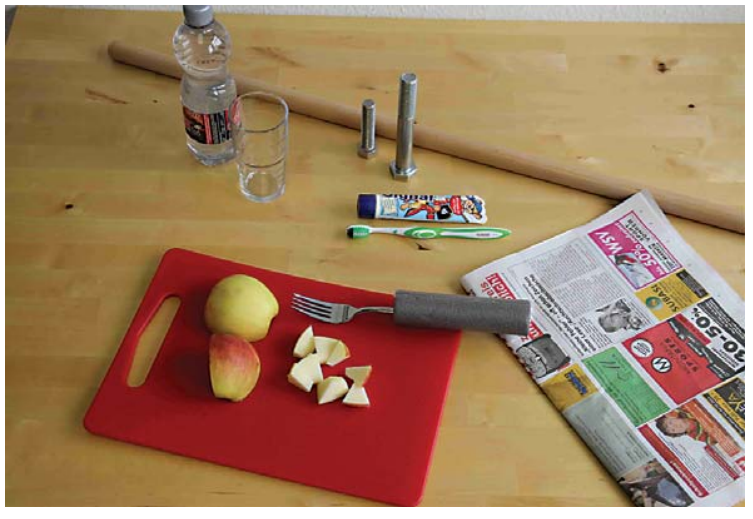

Fig. 1. Test materials.

2. Large bolt: weight about $380 \mathrm{~g}, 15 \mathrm{~cm}$ length, $2 \mathrm{~cm}$ diameter.

3. Toothpaste tube: weight about $60 \mathrm{~g}, 15 \mathrm{~cm}$ length, $3,5 \mathrm{~cm}$ diameter. The tube must have round edges and a cap to screw off and to place the tube on. The tube must be exchanged if there has been toothpaste squeezed out three times. Toothbrush: any no electric.

4. Newspaper: 5 double pages - weight about $80 \mathrm{~g}$. The patient can fold or roll the newspaper, before starting the task.

5. Bottle of water with screw on cap: made of plastic, weight about $500 \mathrm{~g}, 6 \mathrm{~cm}$ diameter. Glass: about $250 \mathrm{ml}$ resistant water glass.

6. Stick: any walking stick or gymnastics stick; the patient carries the stick over 10 steps of a staircase. This may be 10 steps up and in the second assessment of that task 10 steps down, or 5 steps up and 5 steps down in one assessment of the task. With any number of steps available, the patient needs a safe platform to turn. Do not turn at a small platform.

7. Plastic or wooden board, fork with a fork grip of up to $3,5 \mathrm{~cm}$ diameter, boles of preferred food (e.g. apple, cucumber) easy to fork.

\subsubsection{Preparation}

The test material is placed in front of the patient. The test should be realized near a standard table (about $72 \mathrm{~cm}$ height). The patient may sit on a chair or a wheelchair or he or she can perform the tasks while standing. The examiner demonstrates the three versions of each task. The patient executes each task first in the easiest version (1), then in the more demanding (2) and if possible in the most demanding version (3).

The patient should always move the paralyzed hand. To touch the paralyzed hand with the non par- alyzed hand, for example opening the fist or closing the fingers with the healthy hand is not permitted. If the patient uses the healthy limb for assistance, give zero points.

\subsubsection{Assessment}

After an exercise run (see under "Preparing"), each task is repeated three times. Each attempt is videotaped so that the paralyzed hand is always visible. The patient is asked to execute the task so that she or he reaches the highest score as possible. If the patient fails with a more demanding (2) or (3) version of the task she or he can change to the easy version (1). The examiner does not support or touch the patient.

Each attempt to perform the task may not exceed 2 minutes. If the task is not accomplished in this time, it is scored as 0. Exception: carrying the newspaper and carrying the stick are without time limit. If the patient loses the object after grasping or holding it, the task is scored 0 points. Task 7 , eating, is accomplished when the patient eats the peace of food. Even if he or she loses the fork after eating, the task is counted as correct.

If the patient starts with the more difficult version of the task and does not finish this difficult version he or she scores one or two points lower. A particular version of the task has to be completed to score at least one point. If the patient e.g. grasps the newspaper with the paretic hand ( 3 points) but is not able to lay the newspaper on the table but takes the newspaper out of the paralyzed hand with the help of the non-paralyzed hand, the task is scored 1 .

If the patient is unable to walk, tasks 4 and 6 are scored 0 .

The whole manual of the $\mathrm{BzH}$ with photographs and a step-by-step explanation of each task is available in the Supplementary material No 2.

\section{Methods}

BzH was completed in 20 patients after stroke. A group of 15 severely paralyzed stroke patients (8 male) without active finger extension completed a 4-week training in a controlled study with the aim of improving hand function. Fugl-Meyer Assessment (FMA), Motor Activity Log (MAL) Goal Attainment Scaling and the $\mathrm{BzH}$ were assessed before treatment and immediately after treatment. Another 5 stroke patients with hand paresis but with partly residual finger extension have been evaluated and treated in a practice. All patients participated in behavioral physiotherapy. Realistic and meaningful goals have been defined. The patient was 
Table 1

Patient characteristics pre (1) and post (2) treatment

\begin{tabular}{|c|c|c|c|c|c|c|c|c|c|c|c|c|c|c|c|c|}
\hline No & age & $\begin{array}{c}\text { month s } \\
\text { stroke }\end{array}$ & $\begin{array}{l}\text { affected } \\
\text { hand }\end{array}$ & sex & $\begin{array}{c}\text { FMA } \\
\text { tot1 }\end{array}$ & $\begin{array}{r}\text { FMA } \\
\text { hand1 }\end{array}$ & $\begin{array}{c}\text { FMA } \\
\text { arm1 } \\
\end{array}$ & GAS1 & MAL1 & BzH1 & $\begin{array}{c}\text { FMA } \\
\text { tot2 }\end{array}$ & $\begin{array}{r}\text { FMA } \\
\text { hand2 }\end{array}$ & $\begin{array}{l}\text { FMA } \\
\text { arm2 }\end{array}$ & GAS2 & MAL2 & $\mathrm{BzH} 2$ \\
\hline 1 & 51 & 16 & right & $\mathrm{m}$ & 51 & 0 & 2 & 0 & 13 & 3 & 55 & 1 & 4 & 2 & 17 & 9 \\
\hline 2 & 53 & 20 & right & $\mathrm{f}$ & 75 & 4 & 15 & 0 & 0 & 4 & 72 & 3 & 9 & 2 & 2 & 17 \\
\hline 3 & 52 & 156 & right & $\mathrm{f}$ & 59 & 3 & 4 & 0 & 0 & 6 & 58 & 3 & 4 & 0 & 4 & 0 \\
\hline 4 & 55 & 45 & right & $\mathrm{f}$ & 79 & 9 & 12 & 0 & 37 & 20 & 84 & 8 & 16 & 3 & 37 & 28 \\
\hline 5 & 47 & 80 & left & $\mathrm{m}$ & 68 & 3 & 12 & 1 & & 11 & 71 & 3 & 13 & 3 & 27 & 20 \\
\hline 6 & 58 & 28 & left & $\mathrm{m}$ & 56 & 2 & 6 & 0 & 8 & 3 & 56 & 1 & 3 & 1 & 6 & 8 \\
\hline 7 & 47 & 232 & left & $\mathrm{m}$ & 66 & 2 & 11 & 0 & 4 & 2 & 63 & 2 & 8 & 1 & 7 & 8 \\
\hline 8 & 73 & 23 & left & $\mathrm{f}$ & 45 & 0 & 0 & 0 & 0 & 0 & 40 & 0 & 0 & 2 & 0 & 0 \\
\hline 9 & 66 & 23 & right & $\mathrm{f}$ & 68 & 1 & 15 & 0 & 18 & 8 & 77 & 4 & 17 & 1 & 18 & 5 \\
\hline 10 & 54 & 10 & right & $\mathrm{f}$ & 60 & 1 & 6 & 0 & 0 & 0 & 64 & 1 & 12 & 2 & 20 & 5 \\
\hline 11 & 29 & 25 & left & $\mathrm{m}$ & 68 & 1 & 16 & 0 & 15 & 14 & 71 & 3 & 15 & 1 & 15 & 15 \\
\hline 12 & 55 & 17 & left & $\mathrm{m}$ & 61 & 4 & 5 & 0 & 6 & 12 & 61 & 2 & 6 & 1 & 18 & 18 \\
\hline 13 & 66 & 48 & left & $\mathrm{f}$ & 48 & 0 & 0 & 0 & 8 & 0 & 49 & 1 & 1 & 1 & 15 & 0 \\
\hline 14 & 59 & 28 & left & $\mathrm{m}$ & 85 & 8 & 21 & 0 & 10 & 18 & 82 & 7 & 20 & 2 & 15 & 24 \\
\hline 15 & 70 & 23 & right & $\mathrm{m}$ & 63 & 4 & 3 & 0 & 8 & 4 & 67 & 4 & 7 & 3 & 44 & 8 \\
\hline 16 & 63 & 8 & right & $\mathrm{m}$ & & & & & & 26 & & & & & & 42 \\
\hline 17 & 55 & 45 & right & $\mathrm{f}$ & & & & & & 18 & & & & & & 38 \\
\hline 18 & 51 & 13 & left & $\mathrm{m}$ & & & & & & 5 & & & & & & 11 \\
\hline 19 & 72 & 20 & left & $\mathrm{m}$ & & & & & & 7 & & & & & & 13 \\
\hline 20 & 60 & 130 & right & $\mathrm{m}$ & & & & & & 0 & & & & & & 13 \\
\hline
\end{tabular}

asked to plan movements e.g. "extend the fingers", "flex the fingers", "relax". While the patient did so, the physical therapist stimulated the relevant muscles and moved the fingers and the arm passively to stimulate the somatosensory system. When a visible movement or muscle contraction was initiated by the patient, this movement was rewarded. The physical therapist guided the movements, so that most exercises ended in a success experience. To use the hand for daily relevant actions and gait has been included as part of the training. Walking was included in the physical therapy concept because skills of the upper and lower extremity are related (e.g. spasticity of the paralyzed arm increases during walking).

Table 1 Patient characteristics pre (1) and post (2) treatment. Patients 16-20 have been treated with physiotherapy only and completed the BzH pre- and posttreatment but not the Fugl-Meyer Assessment, Goal Attainment Scale and Motor Activity Log.

\subsection{Sensitivity}

Paired sample $t$-tests comparisons were used to detect differences in improvement pre and post-training (FMA scores, MAL, GAS and BzH test scores in 15 patients).

\subsection{Inter-observer reliability}

Inter-observer reliability of the $\mathrm{BzH}$ was calculated with evaluation of 14 videos by 44 examiners (14 Male,
30 Female; mean age \pm SD 25.6 \pm 7.2). Two videos of each task were used. The videos have been selected from a pool of videos of different patients so that different task versions could be shown and that in some cases patients did not succeed in any task version. The examiners had to score each video. Examiners consisted of 4 clinically experienced physiotherapists, 28 physiotherapy students and 12 persons with no medical background. Thirty-eight examiners used the German version of the test manual while 6 examiners used the English version.

\subsection{Test-retest-reliability and validity}

Retest-Reliability was calculated as Pearson correlation coefficient between $\mathrm{BzH}$ pre- and post-treatment scores of 20 patients.

Internal consistency was calculated with Cronbachs alpha.

Percentage of patients who were successful in the different versions of the tasks pre- and post-treatment was calculated to measure task difficulties.

Correlation coefficients between $\mathrm{BzH}$ scores and FMA, MAL and GAS scores respectively were calculated to assess the construct validity of the $\mathrm{BzH}$. The concurrent validity of the BzH with the FMA upper extremity total, FMA motor subscore arm, FMA motor subscore hand, the GAS and with the MAL at pre- and post-treatment was calculated using Pearson's correlation coefficients. 


\section{Results}

\subsection{Sensitivity}

Two-tailed paired-samples $t$-test revealed a significant improvement in $\mathrm{BzH}$ total scores comparing pre- and post-training $(\mathrm{t}(1,14)=-3.191, p=0.007)$ and GAS $(\mathrm{t}(1,14)=-7.483, p=0.000)$, and MAL scores $(\mathrm{t}(1,13)=-2.368, p=0.034)$. Specifically, average $\mathrm{BzH}$ score total \pm standard error (SE) increased from $7 \pm 1.69$ before training to $11 \pm 2.29$ after training; average GAS score total \pm standard error (SE) increased from $0.07 \pm 0.06$ before training to $1.67 \pm 0.23$ after training; average MAL score total \pm standard error (SE) increased from $9.07 \pm 2.65$ before training to $15.57 \pm 3.33$ after training. By contrast, a two-tailed paired-samples $t$-test did not reveal significant improvement from pre- to post-training in FMA total scores $(\mathrm{t}(1,14)=-1.216, p=0.244)$, FMA motor hand scores $(\mathrm{t}(1,14)=-0.397, p=0.698)$, FMA motor arm scores $(\mathrm{t}(1,14)=-0.517, p=0.613)$, respectively (see Fig. 2). In summary, BzH test, GAS and MAL were the only instruments able to detect an improvement after training in comparison with the other instruments namely FMA motor subscales.

Figure 2 BzH scores, FMA sub scores Arm and MAL scores in $N=15$ patients with chronic stroke. The bars indicate the means and standard errors. An asterisk indicates a significant change between the mean of the two measurements pre- training (grey bars) and posttraining (black bars).

\subsection{Inter-rater reliability}

Each examiner rated 14 different videos (two different versions of each of the 7 tasks). For 10 videos agreement between the raters was $100 \%$. For 3 videos agreement was $97.72 \%$ while $88.63 \%$ for the remaining video (Table 2). The mean of percentage of agreement between the raters was very high $(99 \%)$. Table video ratings see Supplement No 3.

\subsection{Test-retest reliability}

We observed a positive and strong correlation between the pre training and post training BzHscores; $r=0.87, n=20, p=0.000$.

\subsection{Internal consistency reliability}

Cronbachs alpha of 0.86 demonstrates good interrelatedness of the items of the test and thus good internal consistency.

\subsection{Task difficulty}

Percent of patients who were successful in different task versions shows no clear hierarchy of difficulty of the tasks. Task 1 "small bolt" shows the highest rate of patients who were successful in version 3 (most difficult). Tasks 3 (toothpaste tube) and 6 (stick) show a high rate of patients who were successful in version 1(easiest) but it seems to be very difficult to reach version 2. Because of variability in percent of patients accomplishing the different versions of the different tasks none of the task seems to be redundant. Rate of success in each task version reflects rehabilitation effects.

\subsection{Validity}

Results of the correlation between BzH scores and the standard instruments for assessment of chronic stroke are shown in Table 2. An asterisk indicates a significant correlation.
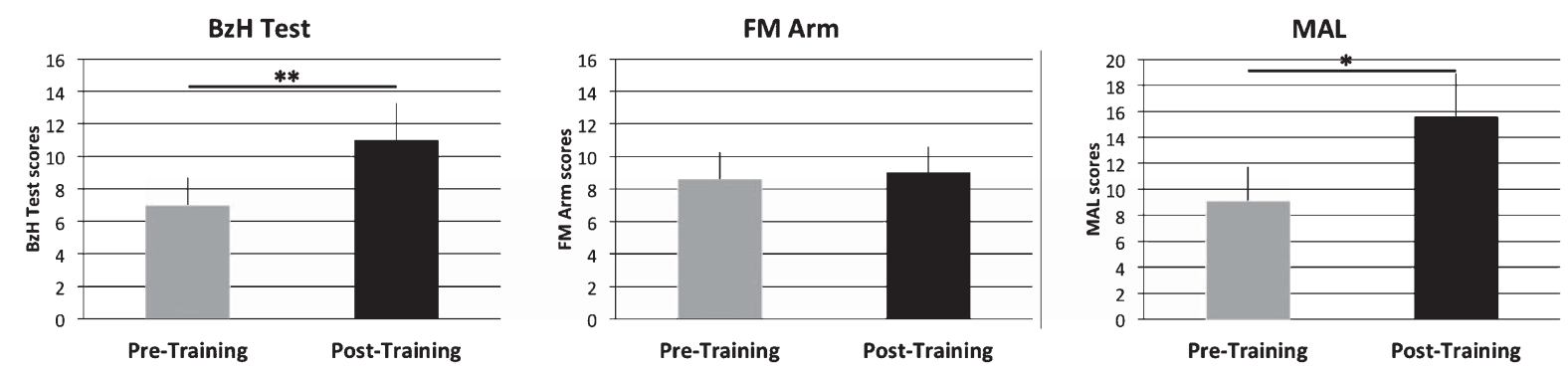

Fig. 2. BzH scores, FMA sub scores Arm and MAL scores. 
Table $2 \mathrm{a}$

Correlation of $\mathrm{BzH}$ with standard assessments - pre-training

\begin{tabular}{lll}
\hline Pearson correlation & \multicolumn{1}{c}{$r$} & $p$-Value \\
\hline BzH pre training scores / FMA upper extremity total pre scores & $0.61 \star$ & $0.016 \star$ \\
BzH pre training scores /FMA motor subscore Arm pre scores & $0.57 \star *$ & $0.027 \star$ \\
BzH pre training scores /FMA motor subscore Hand pre scores & $0.59 \star$ & $0.020 \star$ \\
BzH pre training scores /GAS pre scores & 0.54 & 0.168 \\
BzH pre training scores /MAL pre scores & $0.68 \star$ & $0.0067 \star$ \\
\hline
\end{tabular}

Table $2 b$

Correlation of $\mathrm{BzH}$ with standard assessments - post-training

\begin{tabular}{lll}
\hline Pearson correlation & $r$ & $p$-Value \\
\hline BzH post training scores / FMA upper extremity total post scores & $0.61 \star$ & $0.014 \star$ \\
BzH post training scores /FMA motor subscore Arm post scores & $0.54 \star *$ & $0.034 \star$ \\
BzH post training scores /FMA motor subscore Hand post scores & $0.65 \star$ & $0.008 \star$ \\
BzH post training scores /GAS post scores & $0.50 \star$ & $0.053 \star$ \\
BzH post training scores /MAL post scores & 0.40 & 0.135 \\
\hline
\end{tabular}
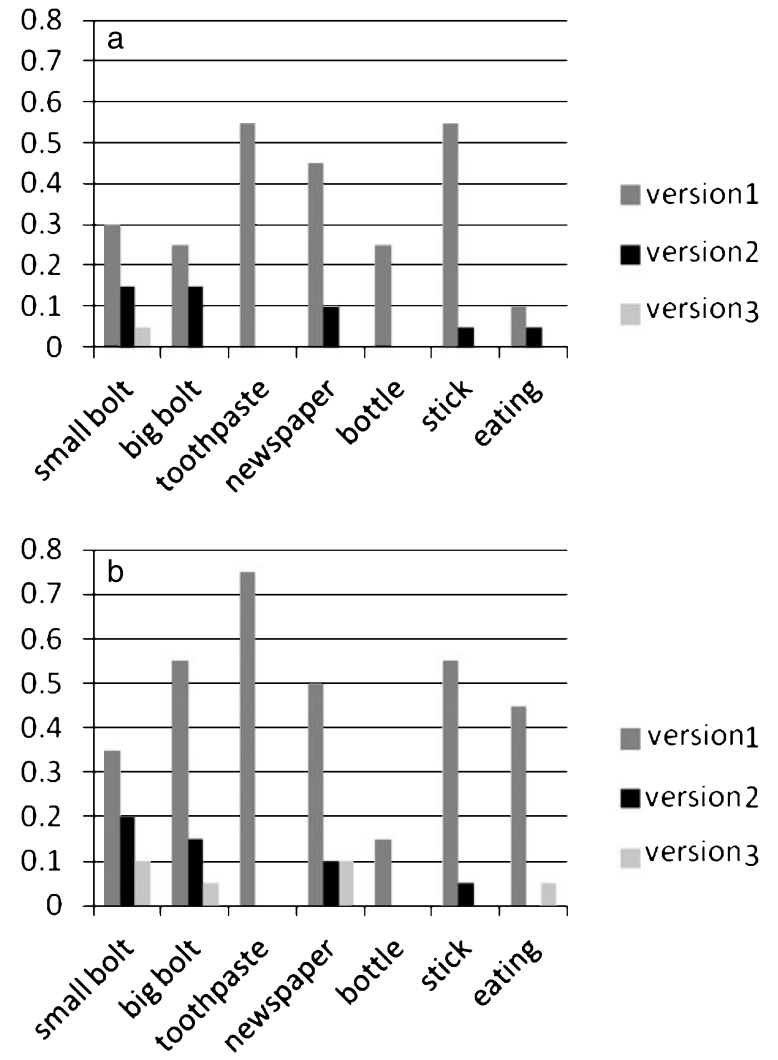

Fig. 3. a. Pre-training: percent of patients who were successful in different task versions. b. Post-training: Percent of patients who were successful in different task versions.

\section{Discussion}

Stroke rehabilitation should achieve goals relevant for daily life. The ability of the patient to cope with daily life challenges can be divided to three domains: (I) Selfcontrol in daily life (II), voluntary movements of the paralyzed arm, hand and leg, and (III) job satisfaction, devotion to personal interests (hobbies) and social participation. Self care and participation (ICF component activity) are possible with one hand and with a minimum of gait function (ICF component function). But all three domains at least in part depend on functional movement capacities (ICF component function).

After stroke a person has to relearn fundamental motor patterns to compensate paralysis and learn several new behaviors to solve old and new problems. The BzH hand-test assesses the patients' ability to use the paralyzed hand with movement patterns relevant for daily life activities (ICF component functions and activities). He or she has to initiate movements and relax the paralyzed hand to hold and release objects (recovery) and has to use the newly learned skills in daily life. We correlated BzH (ICF components function and activity) with the FMA (ICF component function) because both assessment instruments aim to measure upper limb motor function. In addition, correlation with MAL and GAS demonstrates construct validity. Other tests like the ARAT or the WMFT are not doable for these severely paralyzed patients. Instruments that measure ICF components activity like the Barthel Index are independent of recovery and motor function in the paralyzed hand so that this instrument is not useful to demonstrate validity of a hand function and hand activity assessment instrument.

The $\mathrm{BzH}$ is a valid and reliable and highly objective tool to assess daily life relevant motor function and activity in severely paralyzed patients after stroke. It has the potential to measure small changes in function 
in patients with no or negligible limb function. This assessment is thus suitable for research and for rehabilitation of severely paralyzed patients.

The daily life oriented tasks used in the $\mathrm{BzH}$ are also useful as feedback of treatment relevant progress. They provide patients and therapists with ideas and incentives for relevant training exercises. Motor learning principles are at the basis of this measurement instrument such as external focus, clear challenge, incentives of self control, immediate feedback concerning goal attainment.

\subsection{Limitations and future analysis}

Data of more patients and of more centers are needed to confirm the findings of this study.

Test-retest reliability should also be evaluated if the examiners are setting up the patient doing the tests, conducting the test and retest one day later. Furthermore correlation of the BzH and EMG, EEG, fMRI or MEG measurements should demonstrate that the test represents structural brain changes and functional neurophysiological changes.

\section{Conclusions}

The $\mathrm{BzH}$ is the first standardized instrument to reliably assess small changes in hand function and activity of severely paralyzed patients after stroke. The test requires no specialized equipment, is easy to use, and was developed using principles of motor learning. Reliability and validity have been demonstrated.

\section{Acknowledgments}

This work was supported by the Deutsche Forschungsgemeinschaft (DFG), Bundesministerium für Bildung und Forschung (BMBF) Bernstein project Nr. 01GQ0761, European Union (EU, European Research Council - ERC),Werner Reichardt Centre for Integrative Neuroscience (CIN) at the University of Tuebingen (pool project 06-2008).

\section{Declaration of conflicting interests}

The authors declared no potential conflicts of interest.

\section{References}

Adams, R.J., Mador, K., Sethi, K.D., Grotta, J.C., \& Thompson, D.S. (1987). Graded neurological scale for use in acute hemispheric stroke treatment protocols. Stroke, 18, 665-669

Carroll, D.A. (1965). A quantitative test of upper extremity function. J Chronic Disab, 18, 479-491.

Dromerick, A.W., Lang, C.E., Birkenmeier, R., Hahn, M.G., Sahrmann, S.A., Edwards, D.F. (2006). Relationship between upper-limb functional limitation and self-reported disability 3 months after stroke. Journal of Rehabilitation Research \& Development, 43, 401-408.

Duncan, P.M., Wallace, D., Lai, S.L., Johnson, D., Embretson, S., \& Laster, L.J. (1999). The stroke impact scale version 2.0. Evaluation of Reliability, validity and sensitivity to change. Stroke, 30, 2131-2140.

Duncan, P.W., Bode, R.K., Lai, S.M., \& Perera, S. (2003). Rasch analysis of a new stroke-specific outcome scale: The stroke impact scale. ArcivesPhys Med Rehab, 7, 950-963.

Fugl-Meyer, A.R., Jääskö, L., Leyman, I., Olsson, S., \& Steglind, S. (1975). The post-stroke patient. 1. A method for evaluation of physical performance. Scand J Rehabil Med, 7, 13-31.

Heller, A., Wade, D.T., Wood, V.A., Sunderland, A., Langton Hewer, R., Ward, E. (1987). Arm function after stroke: Measurement and recovery over the first three months. Journal of Neurology, Neurosurgery, and Psychiatry, 50, 714-719.

Hurn, J., Kneebone, I., \& Cropley, M. (2006). Goal setting as an outcome measure: A systematic review. Clinical Rehab, 20, 756772.

Kiresuk, T.J., \& Sherman, R.E. (1968). Goal attainment scaling: A general method for evaluating comprehensive community mental health programs. Community Ment Health J, 4, 443-453.

Koski, L., Lin, J.C., Wu, A.D., \& Winstein, C.J. (2007). Reliability of intracortical and corticomotor excitability estimates obtained from the upper extremities in chronic stroke. Neurosci Res, 58, Epub.

Lin, K., Chuang, L., Wu, C., Hsieh, Y., \& Chang, W. (2010). Responsiveness and validity of three dexterous function measures in stroke rehabilitation. Journal of Rehabilitation Research \& Development, 47, 563-572.

Mathiowetz, V., Volland, G., Kashman, N., \& Weber, K. (1985). Adult norms for the Box and Block Test of manual dexterity. Am J OccupTher, 39, 386-391.

Morris, D.M., Uswatte, G., Crago, J.E., Cook, E.W., \& Taub, E. (2001). The Reliability of the Wolf Motor Function Test for Assessing Upper Extremity Function After Stroke. Arch Phys Med Rehabil, 82, 750-755.

Platz, T., \& Pinkowski, C. (2005). Reliability and validity of arm function assessment with standardized guidelines for the FuglMeyer Test, Action Research Arm Test and Box and Block Test: A multicentre study. Clinical Rehabilitation, 19, 404-411.

Shah, S., Vanclay, F., \& Cooper, B. (1989). Improving the sensitivity of the Barthel Index for stroke rehabilitation. J Clin Epidemiol, 42, 703-709.

Sharpless, J.W. (1982). The nine-hole peg test of finger hand coordination for the hemiplegic patient. In: Mossman's A Problem Oriented Approach to Stroke Rehabilitation. Springfield, Illimois: Charles C Thomas, 470-473.

Uswatte, G., Taub, E., Morris, D., Vignolo, M., \& McCulloch, K. (2005). Reliability and Validity of the Upper-Extremity Motor Activity Log-14. Stroke, 36, 2493-2496. 
Wei, X.J., Tong, K.Y., \& Hu, X.L. (2011). The responsiveness and correlation between Fugl-Meyer Assessment, Motor Status Scale and the Action Research Arm Test in chronic stroke with upperextremity rehabilitation robotic training. Int J Rehabil Res, 34, 349-356.

Wolf, S.L., Catlin, P.A., Ellis, M., Link Archer, A., Morgan, B., \& Piacentino, A. (2001). Assessing Wolf Motor Function Test as
Outcome Measure for Research in Patients After Stroke. Stroke, $32,1635-1639$.

Wulf, G., Shea, C., \& Lewthwaite, R. (2010). Motor skill learning and performance: A review of influential factors. Med Educ, 44, 75-84. 
Please mark in the column, "Assessment," which version of the task the patient achieved. You here give automatically the corresponding point. If the patient did not achieve any version of a task, mark 0. Sum the points of all three runs of each task and mark under "Sum". For each task a maximum of (3) points is reachable. The patient should always move the paralyzed hand. Touching the paralyzed hand with the non-paralyzed hand is not allowed. For example, opening the paralyzed fist or closing the paralyzed fingers to grab or hold the object with the help of the non paralyzed hand is not allowed. If the patient does so, the task is scored (0).

1. task - Small-sized bolt

\begin{tabular}{|c|c|c|c|c|}
\hline \multirow[t]{2}{*}{ Score } & \multicolumn{3}{|c|}{ Assessment trial } & \multirow[t]{2}{*}{ Task version } \\
\hline & 1 & 2 & 3 & \\
\hline 0 & ( ) & ( ) & ( ) & - Patient did not succeed in any task \\
\hline 1 & ( ) & ( ) & ( ) & $\begin{array}{l}\text { - Patient pushes the bolt into the paralyzed hand with the help of the non-paralyzed hand } \\
\text { - holds it } \\
\text { - moves the arm to demonstrate the firm grip of the bolt } \\
\text { - drops the bolt out of the paralyzed hand i.e. the bolt can fall }\end{array}$ \\
\hline 2 & ( ) & ( ) & ( ) & $\begin{array}{l}\text { - Patient grasps by pushing the fist down over the bolt placed vertically at the table } \\
\text { - holds it } \\
\text { - moves the arm to demonstrate the firm grip of the bolt } \\
\text { - places or lays the bolt on the table }\end{array}$ \\
\hline 3 & ( ) & ( ) & ( ) & $\begin{array}{l}\text { - Patient grasps the bolt placed vertically at the table from the side } \\
\text { - holds it } \\
\text { - moves the arm to demonstrate the firm grip of the bolt } \\
\text { - places the bolt on the table }\end{array}$ \\
\hline
\end{tabular}

Sum: ... $/ 9$

2. task - Big bolt

\begin{tabular}{|c|c|c|c|c|}
\hline \multirow[t]{2}{*}{ Score } & \multicolumn{3}{|c|}{ Assessment trial } & \multirow[t]{2}{*}{ Task version } \\
\hline & 1 & 2 & 3 & \\
\hline 0 & ( ) & ( ) & ( ) & - Patient did not succeed in any task \\
\hline 1 & ( ) & ( ) & ( ) & $\begin{array}{l}\text { - Patient pushes the bolt into the paralyzed hand with the help of the non-paralyzed hand } \\
\text { - holds it } \\
\text { - moves the arm to demonstrate the firm grip of the bolt } \\
\text { - drops the bolt out of the paralyzed hand i.e. the bolt can fall }\end{array}$ \\
\hline 2 & ( ) & ( ) & ( ) & $\begin{array}{l}\text { - Patient grasps by pushing the fist down over the bolt placed vertically at the table } \\
\text { - holds it } \\
\text { - moves the arm to demonstrate the firm grip of the bolt } \\
\text { - places or lays the bolt on the table }\end{array}$ \\
\hline 3 & ( ) & ( ) & ( ) & $\begin{array}{l}\text { - Patient grasps the bolt placed vertically at the table from the side } \\
\text { - holds it } \\
\text { - moves the arm to demonstrate the firm grip of the bolt } \\
\text { - places the bolt on the table }\end{array}$ \\
\hline
\end{tabular}

Sum: ... 19

3. task - Toothpastetube

\begin{tabular}{|c|c|c|c|c|}
\hline \multirow[t]{2}{*}{ Score } & \multicolumn{3}{|c|}{ Assessment trial } & \multirow[t]{2}{*}{ Task version } \\
\hline & 1 & 2 & 3 & \\
\hline 0 & ( ) & ( ) & ( ) & - Patient did not succeed in any task \\
\hline 1 & ( ) & () & () & $\begin{array}{l}\text { - Patient pushes the toothpaste tube into the paralyzed hand with the help of the } \\
\text { non-paralyzed hand } \\
\text { - holds it } \\
\text { - unscrews the cap } \\
\text { - applies toothpaste to the toothbrush }\end{array}$ \\
\hline
\end{tabular}




\begin{tabular}{|c|c|c|c|c|}
\hline \multirow[t]{2}{*}{ Score } & \multicolumn{3}{|c|}{ Assessment trial } & \multirow{2}{*}{ Task version } \\
\hline & 1 & 2 & 3 & \\
\hline & & & & $\begin{array}{l}\text { - screws on the cap } \\
\text { - takes the toothpaste tube out of the paralyzed hand with the help of the non paralyzed } \\
\text { hand }\end{array}$ \\
\hline 2 & ( ) & ( ) & ( ) & $\begin{array}{l}\text { - Patient grasps the tube vertically placed on the table between thumb and index finger } \\
\text { (pincer grasp) without the help of the non paralyzed hand } \\
\text { - unscrews the cap } \\
\text { - applies toothpaste to the toothbrush } \\
\text { - screws on the cap } \\
\text { - places or lays the tube on the table }\end{array}$ \\
\hline 3 & ( ) & ( ) & ( ) & $\begin{array}{l}\text { - Patient grasps the tube by inverting the hand so that the cap sticks out on the } \\
\text { thumbside of the hand } \\
\text { - unscrews the cap } \\
\text { - applies toothpaste to the toothbrush } \\
\text { - screws on the cap } \\
\text { - places or lays the tube on the table }\end{array}$ \\
\hline
\end{tabular}

Sum: ... $/ 9$

\section{4. task - Newspaper}

\begin{tabular}{|c|c|c|c|c|}
\hline \multirow[t]{2}{*}{ Score } & \multicolumn{3}{|c|}{ Assessment trial } & \multirow[t]{2}{*}{ Task version } \\
\hline & 1 & 2 & 3 & \\
\hline 0 & ( ) & ( ) & ( ) & - Patient did not succeed in any task \\
\hline 1 & ( ) & ( ) & ( ) & $\begin{array}{l}\text { - Patient pushes the newspaper into the paralyzed hand with the help of the non-paralyzed } \\
\text { hand } \\
\text { - holds it } \\
\text { - carries it } 5 \text { meters } \\
\text { - takes it out of the paralyzed hand with the help of the non-paralyzed hand }\end{array}$ \\
\hline 2 & ( ) & ( ) & () & $\begin{array}{l}\text { - Patient pushes the newspaper into the paralyzed hand with the help of the non-paralyzed } \\
\text { hand } \\
\text { - holds it } \\
\text { - carries it } 5 \text { meters } \\
\text { - lays the newspaper on the table }\end{array}$ \\
\hline 3 & ( ) & ( ) & ( ) & $\begin{array}{l}\text { - Patient grasps the newspaper with the paretic hand, after using the healthy hand to } \\
\text { bring it to a comfortable position for grasping } \\
\text { - holds it } \\
\text { - carries it } 5 \text { meters } \\
\text { - lays the newspaper on the table }\end{array}$ \\
\hline
\end{tabular}

Sum: ... 19

\section{5. task - Bottle of water with screw on cap}

\begin{tabular}{|c|c|c|c|c|}
\hline \multirow[t]{2}{*}{ Score } & \multicolumn{3}{|c|}{ Assessment trial } & \multirow[t]{2}{*}{ Task version } \\
\hline & 1 & 2 & 3 & \\
\hline 0 & ( ) & ( ) & ( ) & - Patient did not succeed in any task \\
\hline 1 & ( ) & () & () & $\begin{array}{l}\text { - Patient pushes the bottle into the paralyzed hand with the help of the non-paralyzed hand } \\
\text { - holds it } \\
\text { - unscrews the cap } \\
\text { - pours water into a glass } \\
\text { - screws on the cap } \\
\text { - takes the bottle out of the paralyzed hand with the help of the non-paralyzed hand }\end{array}$ \\
\hline 2 & ( ) & ( ) & ( ) & $\begin{array}{l}\text { - Patient grasps by pushing the fist down over the bottle placed vertically on the table } \\
\text { - unscrews the cap } \\
\text { - pours water into a glass } \\
\text { - screws on the cap } \\
\text { - places or lays the bottle on the table }\end{array}$ \\
\hline
\end{tabular}




\begin{tabular}{|c|c|c|c|c|}
\hline \multirow[t]{2}{*}{ Score } & \multicolumn{3}{|c|}{ Assessment trial } & \multirow[t]{2}{*}{ Task version } \\
\hline & 1 & 2 & 3 & \\
\hline 3 & ( ) & () & () & $\begin{array}{l}\text { - Patient grasps the bottle placed vertically on the table from the side } \\
\text { - unscrews the cap } \\
\text { - pours water into a glass } \\
\text { - screws on the cap } \\
\text { - places the bottle on the table }\end{array}$ \\
\hline
\end{tabular}

Sum: ... 19

\section{6. task - Stick}

\begin{tabular}{|c|c|c|c|c|}
\hline \multirow[t]{2}{*}{ Score } & \multicolumn{3}{|c|}{ Assessment trial } & \multirow[t]{2}{*}{ Task version } \\
\hline & 1 & 2 & 3 & \\
\hline 0 & ( ) & ( ) & ( ) & - Patient did not succeed in any task \\
\hline 1 & ( ) & ( ) & ( ) & $\begin{array}{l}\text { - Patient pushes the stick into the paralyzed hand with the help of the non-paralyzed hand } \\
\text { - holds it } \\
\text { - carries the stick over ten steps of a staircase } \\
\text { - takes the stick out of the paralyzed hand with the help of the non-paralyzed hand }\end{array}$ \\
\hline 2 & ( ) & ( ) & ( ) & $\begin{array}{l}\text { - Patient grasps the stick with the paretic hand, after using the healthy hand to bring it to } \\
\text { a comfortable position for grasping } \\
\text { - carries the stick over ten steps of a staircase } \\
\text { - releases the stick and takes the stick out of the paralyzed hand with the help of the } \\
\text { non-paralyzed hand }\end{array}$ \\
\hline
\end{tabular}

Sum: ... /6

\section{7. task - Eating}

\begin{tabular}{|c|c|c|c|c|}
\hline \multirow[t]{2}{*}{ Score } & \multicolumn{3}{|c|}{ Assessment trial } & \multirow[t]{2}{*}{ Task version } \\
\hline & 1 & 2 & 3 & \\
\hline 0 & ( ) & ( ) & () & - Patient did not succeed in any task \\
\hline 1 & & & & $\begin{array}{l}\text { - Examiner forks a piece of food (e.g apple) with the fork } \\
\text { - Patient grasps the fork with the non-paralyzed hand } \\
\text { - pushes the fork into the paralyzed hand } \\
\text { - holds it } \\
\text { - brings the fork to the mouth and eats the food }\end{array}$ \\
\hline 2 & ( ) & ( ) & ( ) & $\begin{array}{l}\text { - Patient takes the fork with the non paralyzed hand - pushes the fork into the paralyzed hand } \\
\text { - holds it } \\
\text { - patient forks a piece of food with the fork } \\
\text { - brings the fork to the mouth and eats the food }\end{array}$ \\
\hline 3 & ( ) & ( ) & ( ) & $\begin{array}{l}\text { - Patient grasps the fork, which is laying on the table, with the paralyzed hand } \\
\text { - holds it } \\
\text { forks a piece of food with the fork } \\
\text { - brings the fork to the mouth and eats the food }\end{array}$ \\
\hline
\end{tabular}

Sum: ... $/ 9$

Total value .../ /60 


\section{A new hand test for rehabilitation effects in severely affected stroke patients}

The instrument consists of seven daily life-oriented tasks that the patient is asked to perform in a standardized manner. The tasks demand different complex movements of the paralyzed hand, forearm and upper arm. Evasive movements and faking movements of the paralyzed arm and hand are explicitly allowed. The test aims to assess the daily life functionability and at the same time to motivate the patient and the therapists to exercise and use such actions in daily life.

Each task can be performed in three different versions (words in bolt mark the aspects of the task that change from one version to the other) e.g. (1) -Patient pushes the newspaper into the paralyzed hand with the help of the non paralyzed hand - holds it- carries it 5 meters while walking- grabs it from the paralyzed hand with the help of the non paralyzed hand - (2) - Patient pushes the newspaper into the paralyzed hand with the help of the non paralyzed hand- holds it- carries it 5 meters lays the newspaper on the table - (3) - Patient grasps the newspaper with the paretic hand, after using the healthy hand to bring it to a comfortable position for grasping - holds it - carries it 5 meters - lays the newspaper on the table.

The tasks are ranked from easy to difficult and are rated with (1) to (3) points. If the patient did not accomplish any version of the task, it is rated as zero.

\section{Test Material}

1. Small-sized bolt: weight about $130 \mathrm{~g}, 8 \mathrm{~cm}$ length, $1.7 \mathrm{~cm}$ diameter.

2. Large bolt: weight about $380 \mathrm{~g}, 15 \mathrm{~cm}$ length, $2 \mathrm{~cm}$ diameter.

3. Toothpaste tube: weight about $60 \mathrm{~g}, 15 \mathrm{~cm}$ length, $3.5 \mathrm{~cm}$ diameter. The tube must have round edges and a cap to screw off and to place the tube on. The tube must be exchanged if there has been squeezed out toothpaste three times. Toothbrush: any.

4. Newspaper: 5 double pages - weight about $80 \mathrm{~g}$. The patient can fold or roll the newspaper, before starting the item.

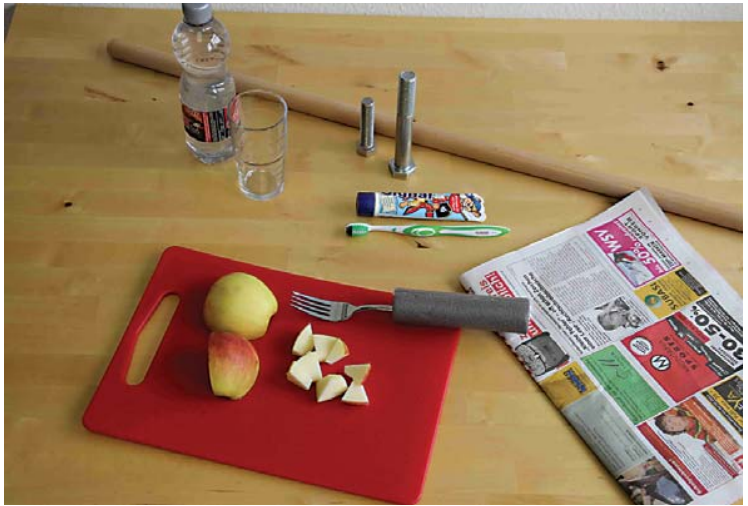

5. Bottle of water with screw on cap: made of plastic, weight about $500 \mathrm{~g}, 6 \mathrm{~cm}$ diameter. Glass: about $250 \mathrm{ml}$ resistant water glass.

6. Stick: any walking stick or gymnastics stick; the patient carries the stick over 10 steps of a staircase. This may be 10 steps up and in the second assessment of that task 10 steps down, or 5 steps up and 5 steps down in one assessment of the task. With any number of steps available, the patient needs a safe platform to turn. Do not turn at a small platform.

7. Plastic or wooden board, fork with a fork grip of up to $3.5 \mathrm{~cm}$ diameter, boles of preferred food (e.g. apple, cucumber) easy to fork.

\section{Preparing}

The test material is placed in front of the patient. The test should be realized near a standard table (about $72 \mathrm{~cm}$ height). The patient may sit on a chair or a wheelchair or he or she can perform the tasks while standing. The examiner informs the patient and demonstrates the three versions of each task. The patient exercises each task first in the easiest version (1), then in the more demanding (2) and if possible in the most demanding version (3).

The patient should always move the paralyzed hand. To touch the paralyzed hand with the 
non-paralyzed hand, for example opening the fist or closing the fingers with the healthy hand is not permitted. If the patient uses the healthy limb for assistance, give zero points.

\section{Assessment}

After the exercise run, each task is repeated three times. Each attempt is videotaped. The patient is asked to execute the task so that she or he reaches the highest attempt score as possible. If the patient fails with a more demanding (2) or (3) version of the task she or he can change to the easy version (1). The examiner does not support or touch the patient and does not demonstrate movements.

Each attempt to perform the task may not exceed 2 minutes. If the task is not accomplished in this time,

\section{Small sized bolt}

\section{Big bolt}

(0) The patient did not succeed in any task. e.g. - touches the paralyzed hand with the nonparalyzed hand to open the fist or to close the fingers over the object; - is not able to push the bolt into the fist; loses the bolt before moving the arm; is not able to let the bolt go; needs more than 2 minutes to complete the task

(1) The patient pushes the bolt into the paralyzed hand with the help of the non paralyzed hand holds it - moves the arm to demonstrate the firm grip of the bolt -drops the bolt out of the paralyzed hand $(2 \mathrm{a}-\mathrm{c})$.
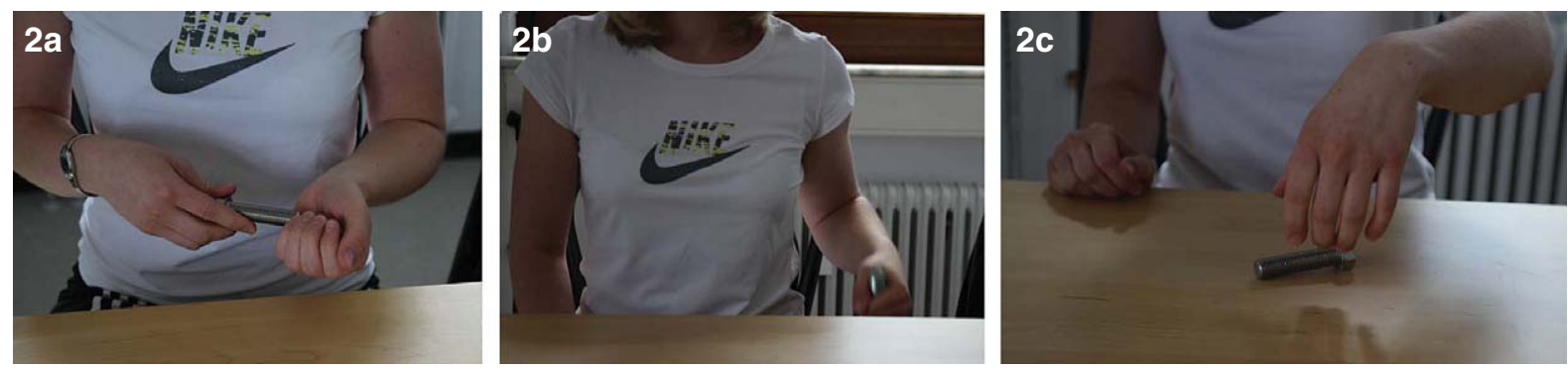

it is counted as (0) points. Exception: carrying the newspaper and carrying the stick are without time limit. If the patient loses the object after grasping or holding it, the task is assessed with 0 points. Task 7, eating, is accomplished when the patient eats the peace of food. Even if he or she loses the fork after eating, the task calculated as correct.

If the patient starts with the more difficult version of the task and does not finish this difficult version he or she scores one or two points lower. A particular version of the task has to be completed to score at least one point. If the patient e.g. grasps the newspaper with the paretic hand ( 3 points) but is not able to lay the newspaper on the table but takes the newspaper out of the paralyzed hand with the help of the non-paralyzed hand, the task is scored 1.

If the patient is unable to walk, tasks 4 and 6 are scored 0 .

Please indicate in the middle column under assessment trials $1 / 2 / 3$ which version of the task the patient achieved. You here give automatically the corresponding point. If the patient did not achieve any version of a task, mark (0). Sum the points of all three runs of each task and mark under "Sum".

(2) The patient grasps by pushing the fist down over the bolt placed vertically at the table (the bolt may not be held or touched with the non paralyzed hand, if the patient does so, the task is scored (1))- moves the arm to demonstrate the firm grip of the bolt - places or lays the bolt on the table $(2 \mathrm{~d}, \mathrm{e})$

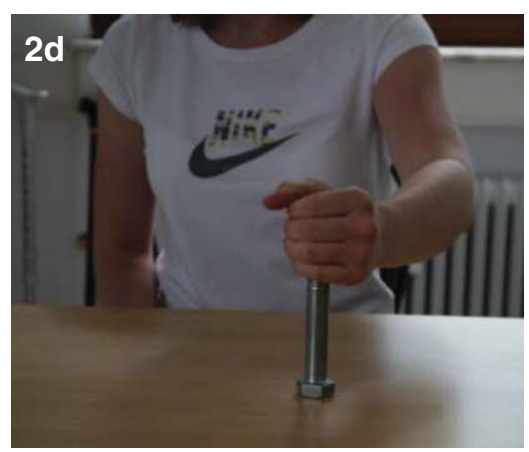




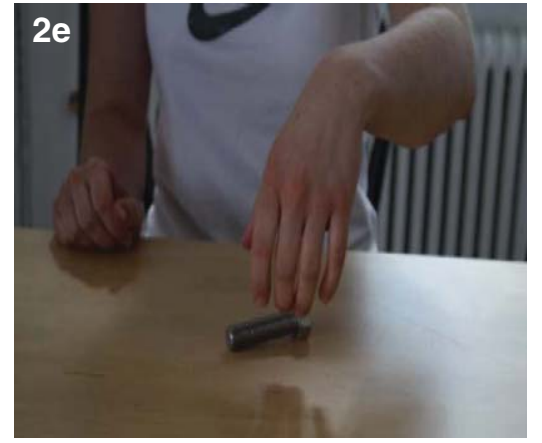

(3) The patient grasps the bolt placed vertically at the table from the side - moves the arm to demonstrate the firm grip of the bolt - places the bolt on the table (2f, g)
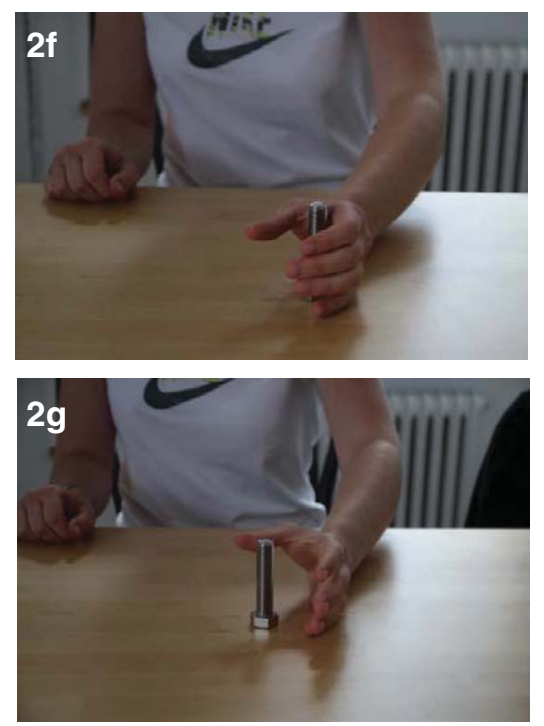

\section{Toothpaste tube}

(0) The patient did not succeed in any task. e.g. - touches the paralyzed hand with the nonparalyzed hand to open the fist or to close the fingers over the object; - is not able to push the toothpasttube into the fist; is not able to press out
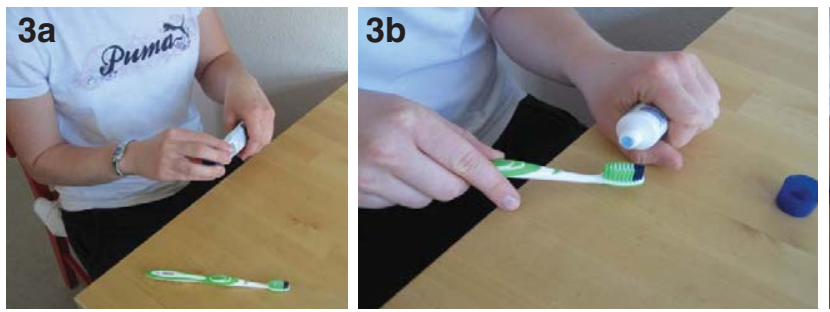

paste; loses the tube before screwing on the cap; needs more than 2 minutes to complete the task.

(1) The patient pushes the toothpaste tube into the paralyzed hand with the help of the non paralyzed hand - holds it - unscrews the cap - applies toothpaste to the toothbrush - screws on the cap - takes the toothpaste tube out of the paralyzed hand with the help of the non paralyzed hand (3a-d)

(2) The patient grasps the tube vertically placed on the table between thumb and index finger (pincer grasp) without the help of the non paralyzed hand - unscrews the cap - applies toothpaste to the toothbrush - screws on the cap - places or lays the tube on the table $(3 e, f)$
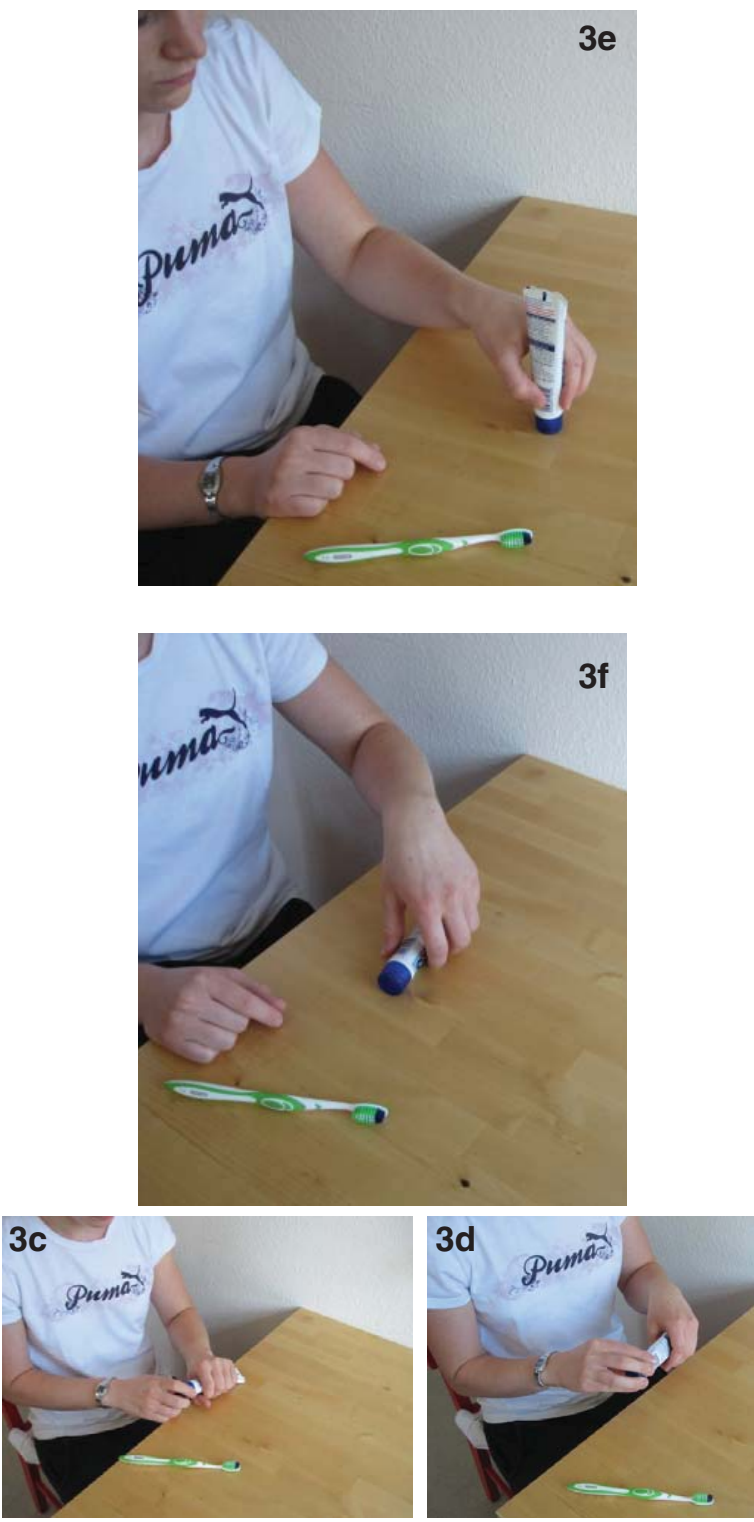
(3) The patient grasps the tube by inverting the hand so that the cap sticks out on the thumbside of the hand - unscrews the cap - applies toothpaste to the toothbrush - screws on the cap - places or lays the tube on the table without any help of the non paralyzed hand $(3 g)$

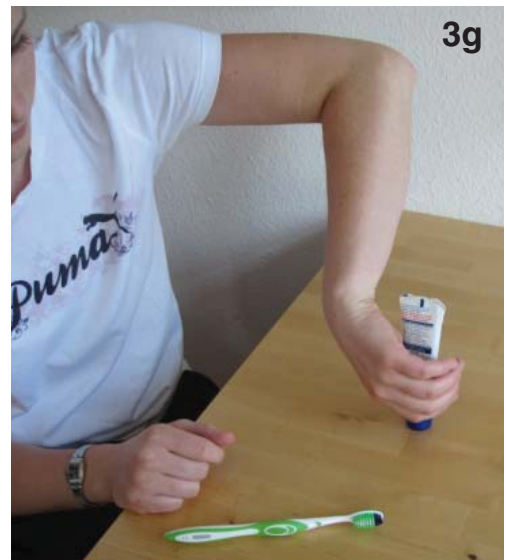

\section{Newspaper}

(0) The patient did not succeed in any task e.g. touches the paralyzed hand with the nonparalyzed hand to open the fist or to close the fingers with the healthy hand; - is not able to push the newspaper into the paralyzed hand; loses the newspaper before walking 5 meters

(1) The patient pushes the newspaper into the paralyzed hand with the help of the non-paralyzed hand - holds it - carries it 5 meters - takes it out of the paralyzed hand with the help of the non-paralyzed hand $(4 a-c)$

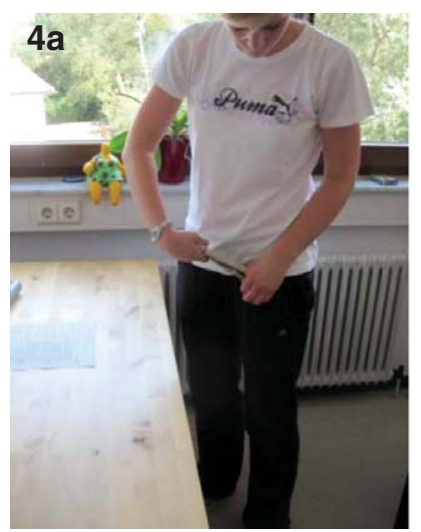

(2) The patient pushes the newspaper into the paralyzed hand with the help of the non-paralyzed hand - holds it - carries it 5 meters - lays the newspaper on the table $(4 \mathrm{~d})$

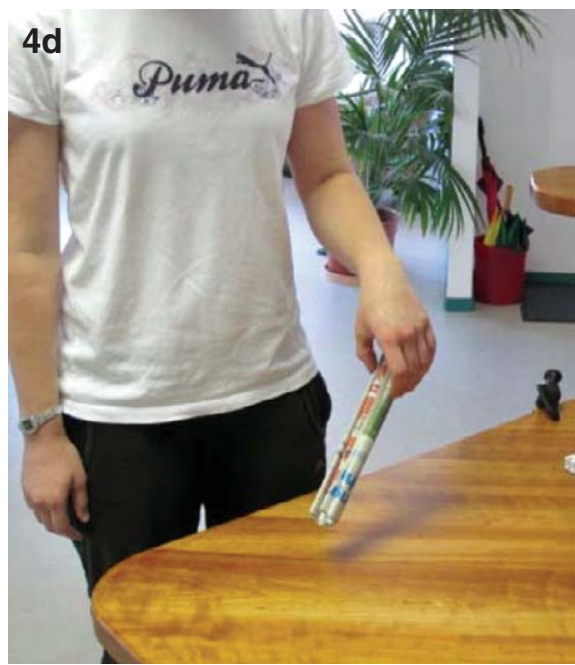

(3) The patient grasps the newspaper with the paretic hand, after using the healthy hand to bring it to a comfortable position for grasping - holds it - carries it 5 meters - lays the newspaper on the table $(4 \mathrm{e})$
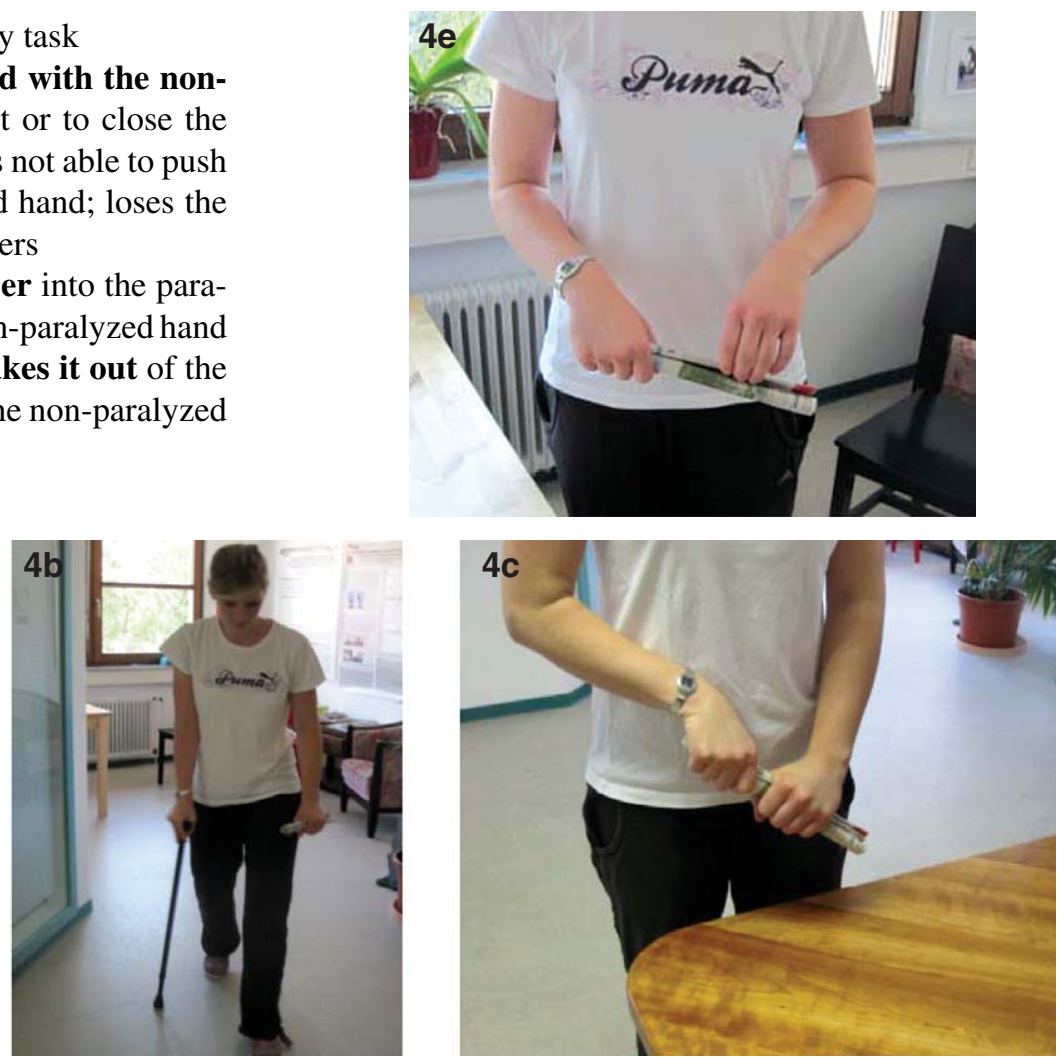


\section{Bottle of water with screw on cap}

(0) The patient did not succeed in any task. e.g. - touches the paralyzed hand with the nonparalyzed hand to open the fist or to close the fingers over the object; - is not able to push the bottle into the fist; loses the bottle before screwing on the cap; is not able to pour water into a glas; needs more than 2 minutes to complete the task
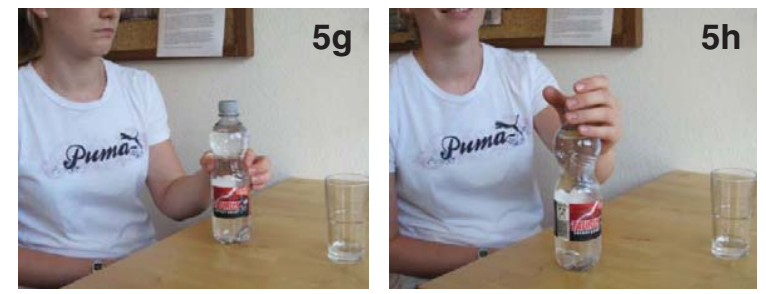
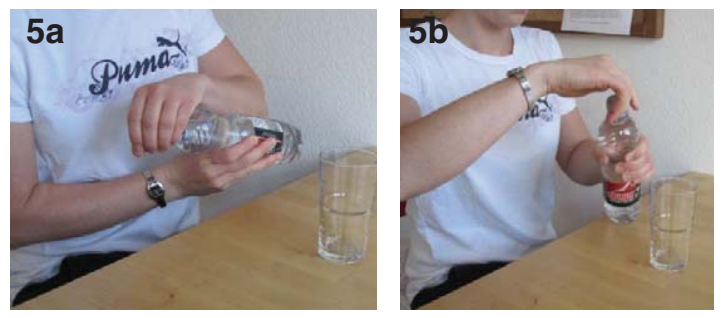

(1) The patient pushes the bottle into the paralyzed hand with the help of the non-paralyzed hand holds it - unscrews the cap with the non paralyzed hand - pours water into a glass with the paralyzed hand - screws on the cap - takes the bottle out of the paralyzed hand with the help of the nonparalyzed hand $(5 \mathrm{a}-\mathrm{d})$

(2) The patient grasps by pushing the fist down over the bottle placed vertically on the table (the bottle may not be held or touched with the non-paralyzed hand, if the patient does so, the task is scored (1)) - unscrews the cap with the non paralyzed hand pours water into a glass with the paralyzed hand - screws on the cap - places or lays the bottle on the table without the help of the non-paralyzed hand $(5 e, f)$
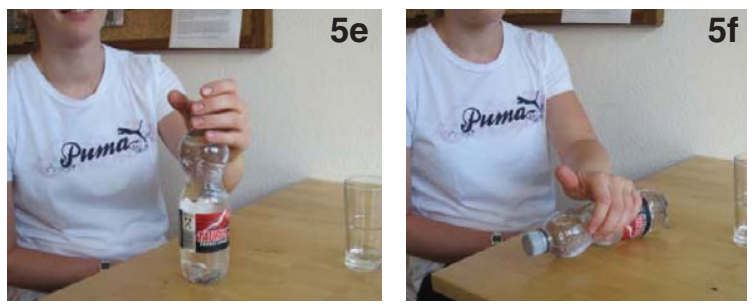

(3) The patient grasps the bottle placed vertically on the table from the side - unscrews the cap with the non paralyzed hand - pours water into a glass with the paralyzed hand - screws on the cap - places the bottle on the table without the help of the nonparalyzed hand $(5 \mathrm{~g}, \mathrm{~h})$
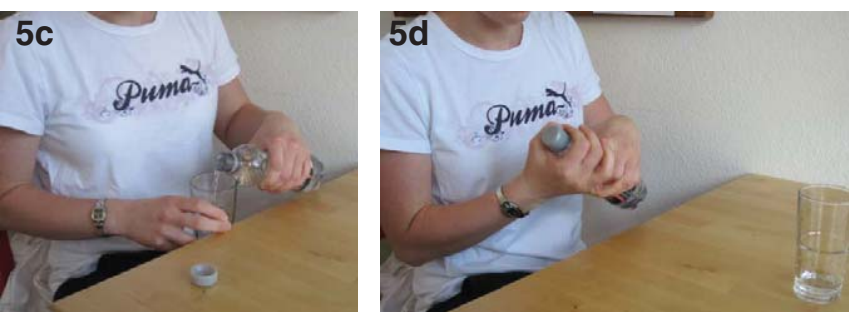

\section{Stick}

(0) The patient did not succeed in any task. e.g. - touches the paralyzed hand with the nonparalyzed hand to open the fist or to close the fingers over the object; - is not able to push the stick into the fist; loses the stick before walking 10 steps

(1) The patient pushes the stick into the paralyzed hand with the help of the non-paralyzed hand holds it - carries the stick over ten steps of a staircase - takes the stick out of the paralyzed hand with the help of the non-paralyzed hand $(6 a-c)$

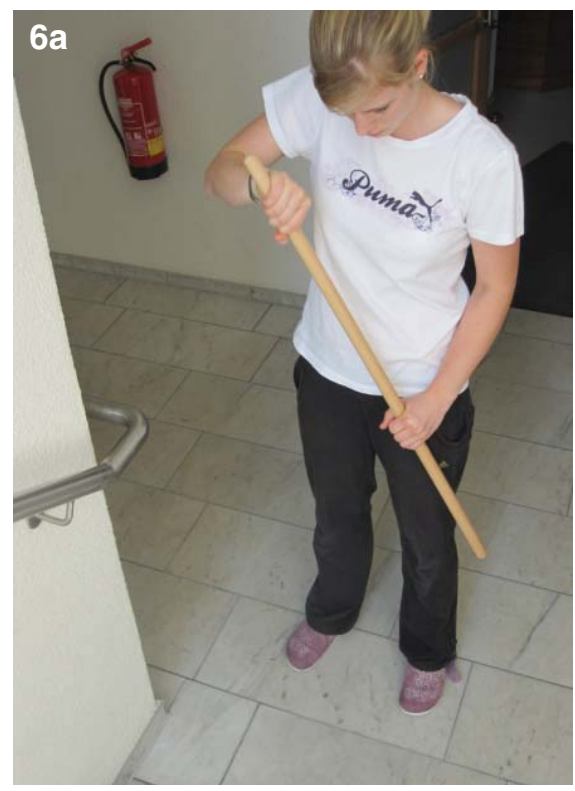



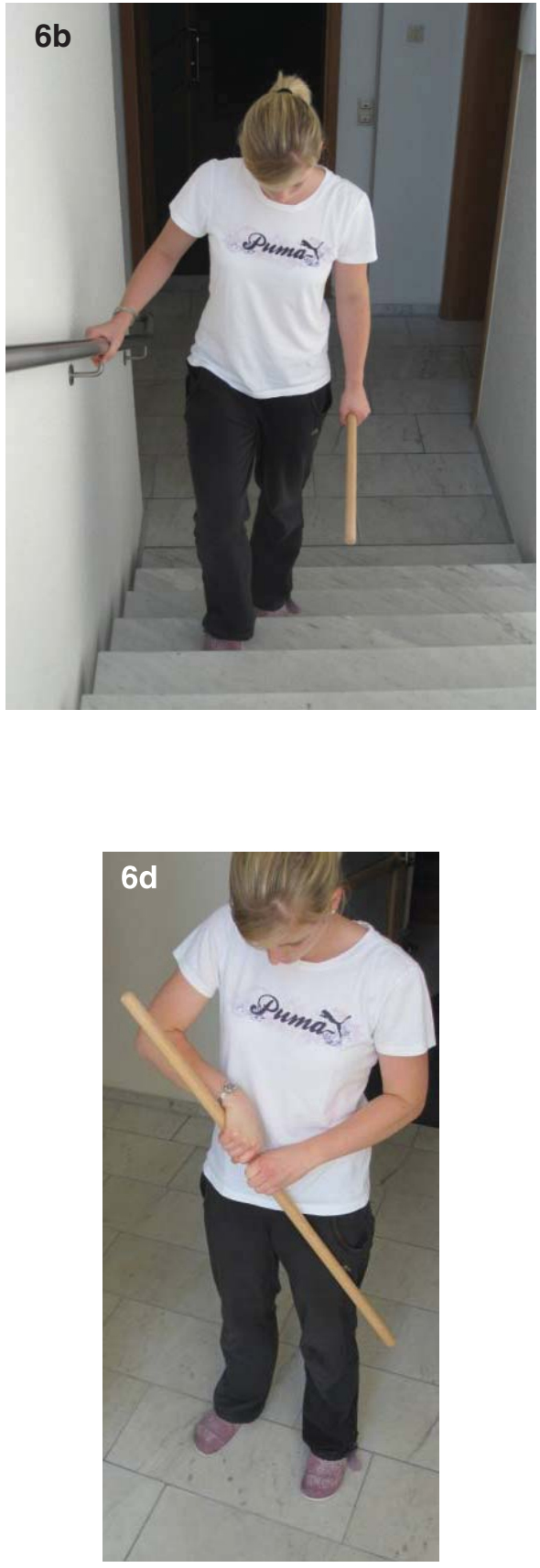

(2) The patient grasps the stick with the paretic hand, after using the healthy hand to bring it to a comfortable position for grasping - carries the stick over ten steps of a staircase - releases the stick and takes the stick out of the paralyzed hand with the help of the non-paralyzed hand $(6 \mathrm{~d}, \mathrm{e})$
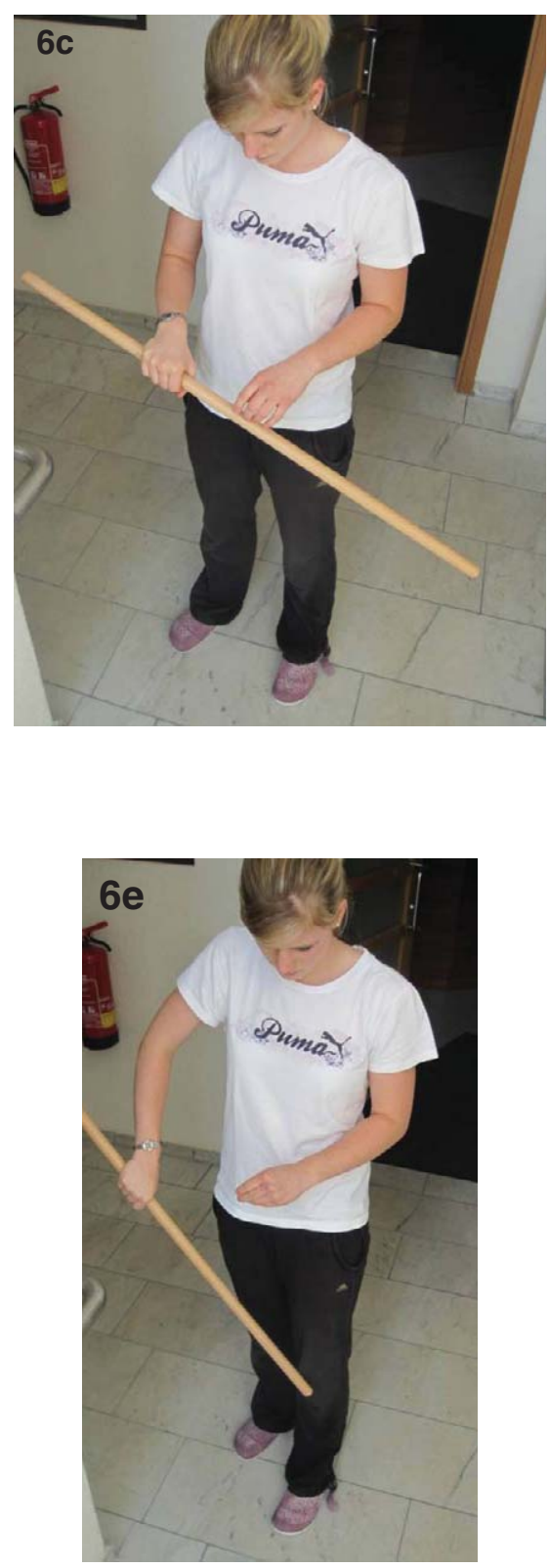

\section{Eating}

(0) The patient did not succeed in any task. e.g. - touches the paralyzed hand with the nonparalyzed hand to open the fist or to close the fingers over the object; - is not able to push the fork into the fist; is not able to lift the arm and bring the peace of food to the mouth; loses the fork before eating the peace of food; needs more than 2 minutes to complete the task 
(1) The examiner forks a piece of food (e.g apple) with the fork - the patient grasps the fork with the non-paralyzed hand - pushes the fork into the paralyzed hand - holds it -brings the fork to the mouth and eats the food $(7 a-c)$
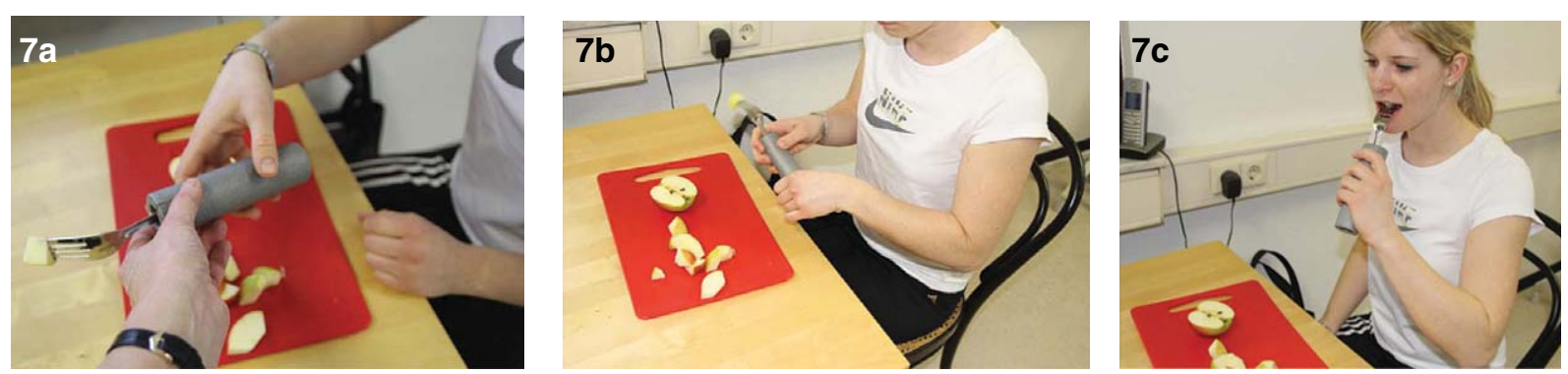

(2) The patient takes the fork with the non-paralyzed hand - pushes the fork into the paralyzed hand holds it - forks a piece of food with the fork brings the fork to the mouth and eats the food (7d)

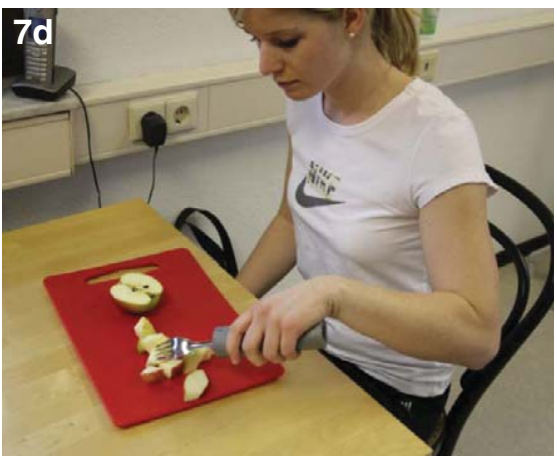

(3) The patient grasps the fork, which is laying on the table, with the paralyzed hand - holds it - forks a piece of food with the fork - brings the fork to the mouth and eats the food (7e)

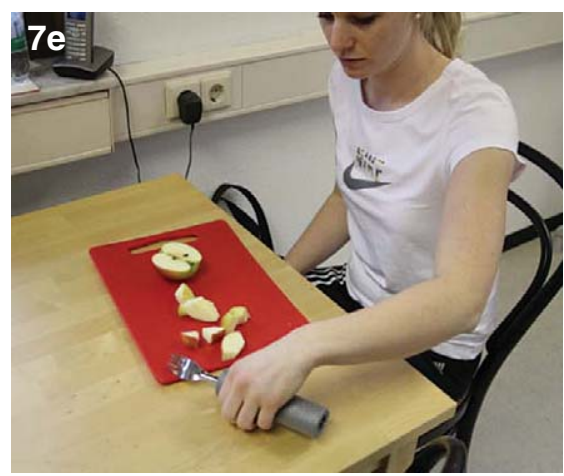


Table 1

Percent agreement between the raters for 14 videos. $V=$ video

\begin{tabular}{|c|c|c|c|c|c|c|c|c|c|c|c|c|c|c|}
\hline Observers & V1 & $\mathrm{V} 2$ & V3 & V4 & V5 & V6 & V7 & V8 & V9 & V10 & V11 & V12 & V13 & $\overline{\mathrm{V} 14}$ \\
\hline 1 & 0 & 3 & 1 & 3 & 1 & 1 & 2 & 2 & 3 & 0 & 1 & 0 & 1 & 3 \\
\hline 2 & 0 & 3 & 1 & 3 & 1 & 1 & 2 & 3 & 3 & 0 & 1 & 0 & 1 & 3 \\
\hline 3 & 0 & 3 & 1 & 3 & 1 & 1 & 2 & 3 & 3 & 0 & 1 & 0 & 1 & 3 \\
\hline 4 & 0 & 3 & 1 & 3 & 1 & 1 & 2 & 3 & 3 & 0 & 1 & 0 & 1 & 3 \\
\hline 5 & 0 & 3 & 1 & 3 & 1 & 1 & 2 & 3 & 3 & 0 & 1 & 0 & 1 & 3 \\
\hline 6 & 0 & 3 & 1 & 3 & 1 & 1 & 2 & 3 & 3 & 0 & 1 & 0 & 1 & 3 \\
\hline 7 & 0 & 3 & 1 & 3 & 1 & 1 & 2 & 3 & 3 & 0 & 1 & 0 & 1 & 3 \\
\hline 8 & 0 & 3 & 1 & 3 & 1 & 1 & 2 & 3 & 3 & 0 & 1 & 0 & 1 & 3 \\
\hline 9 & 0 & 3 & 1 & 3 & 1 & 1 & 2 & 3 & 3 & 0 & 1 & 0 & 1 & 3 \\
\hline 10 & 0 & 3 & 1 & 3 & 1 & 1 & 2 & 3 & 3 & 0 & 1 & 0 & 1 & 3 \\
\hline 11 & 0 & 3 & 1 & 3 & 1 & 1 & 2 & 3 & 3 & 0 & 1 & 0 & 1 & 3 \\
\hline 12 & 0 & 3 & 1 & 3 & 1 & 1 & 2 & 3 & 3 & 0 & 1 & 0 & 1 & 3 \\
\hline 13 & 0 & 3 & 1 & 3 & 1 & 1 & 2 & 3 & 3 & 0 & 1 & 0 & 1 & 3 \\
\hline 14 & 0 & 3 & 1 & 3 & 1 & 1 & 2 & 3 & 3 & 0 & 1 & 0 & 1 & 3 \\
\hline 15 & 0 & 3 & 1 & 3 & 1 & 1 & 2 & 3 & 3 & 0 & 1 & 0 & 1 & 3 \\
\hline 16 & 0 & 3 & 1 & 3 & 1 & 1 & 2 & 3 & 3 & 0 & 1 & 0 & 1 & 3 \\
\hline 17 & 0 & 3 & 1 & 3 & 1 & 1 & 2 & 3 & 3 & 0 & 1 & 0 & 1 & 3 \\
\hline 18 & 0 & 3 & 1 & 3 & 1 & 1 & 2 & 3 & 3 & 0 & 1 & 0 & 1 & 3 \\
\hline 19 & 0 & 3 & 1 & 3 & 1 & 1 & 2 & 3 & 3 & 0 & 1 & 0 & 1 & 3 \\
\hline 20 & 0 & 3 & 1 & 3 & 1 & 1 & 2 & 3 & 3 & 0 & 1 & 0 & 1 & 3 \\
\hline 21 & 0 & 3 & 1 & 3 & 1 & 1 & 2 & 2 & 3 & 0 & 1 & 0 & 1 & 3 \\
\hline 22 & 0 & 3 & 1 & 3 & 1 & 1 & 2 & 3 & 3 & 0 & 1 & 0 & 1 & 3 \\
\hline 23 & 0 & 3 & 1 & 3 & 1 & 1 & 2 & 3 & 3 & 0 & 1 & 0 & 1 & 3 \\
\hline 24 & 0 & 3 & 1 & 3 & 1 & 1 & 2 & 3 & 3 & 0 & 1 & 0 & 1 & 3 \\
\hline 25 & 0 & 3 & 0 & 3 & 1 & 1 & 2 & 3 & 3 & 0 & 1 & 0 & 1 & 3 \\
\hline 26 & 0 & 3 & 1 & 3 & 1 & 1 & 2 & 3 & 3 & 0 & 1 & 0 & 1 & 3 \\
\hline 27 & 0 & 3 & 1 & 3 & 1 & 1 & 2 & 3 & 3 & 0 & 1 & 0 & 1 & 3 \\
\hline 28 & 0 & 3 & 1 & 3 & 1 & 1 & 2 & 3 & 3 & 0 & 1 & 0 & 1 & 3 \\
\hline 29 & 0 & 3 & 1 & 3 & 1 & 1 & 2 & 2 & 3 & 0 & 1 & 0 & 1 & 3 \\
\hline 30 & 0 & 3 & 1 & 3 & 1 & 1 & 2 & 3 & 3 & 0 & 1 & 0 & 1 & 3 \\
\hline 31 & 0 & 3 & 1 & 3 & 1 & 1 & 2 & 2 & 3 & 0 & 1 & 0 & 1 & 3 \\
\hline 32 & 0 & 3 & 1 & 3 & 1 & 1 & 2 & 3 & 3 & 0 & 1 & 0 & 1 & 3 \\
\hline 33 & 0 & 3 & 1 & 3 & 1 & 1 & 2 & 3 & 3 & 0 & 1 & 0 & 1 & 3 \\
\hline 34 & 0 & 3 & 1 & 3 & 1 & 1 & 3 & 3 & 3 & 0 & 1 & 0 & 1 & 3 \\
\hline 35 & 0 & 3 & 1 & 3 & 1 & 1 & 2 & 3 & 3 & 0 & 1 & 0 & 1 & 3 \\
\hline 36 & 0 & 3 & 1 & 3 & 1 & 1 & 2 & 3 & 3 & 0 & 1 & 0 & 1 & 3 \\
\hline 37 & 0 & 3 & 1 & 3 & 1 & 1 & 2 & 3 & 3 & 0 & 1 & 0 & 1 & 3 \\
\hline 38 & 0 & 3 & 1 & 3 & 1 & 1 & 2 & 3 & 3 & 0 & 1 & 0 & 1 & 3 \\
\hline 39 & 0 & 3 & 1 & 3 & 1 & 1 & 2 & 3 & 3 & 0 & 1 & 0 & 1 & 3 \\
\hline 40 & 0 & 3 & 1 & 3 & 1 & 1 & 2 & 3 & 3 & 0 & 1 & 0 & 1 & 3 \\
\hline 41 & 0 & 3 & 1 & 3 & 1 & 1 & 2 & 3 & 3 & 0 & 1 & 0 & 1 & 3 \\
\hline 42 & 0 & 3 & 1 & 3 & 1 & 1 & 2 & 3 & 3 & 0 & 0 & 0 & 1 & 3 \\
\hline 43 & 0 & 3 & 1 & 3 & 1 & 1 & 2 & 3 & 3 & 0 & 1 & 0 & 1 & 3 \\
\hline 44 & 0 & 3 & 1 & 3 & 1 & 1 & 2 & 2 & 3 & 0 & 1 & 0 & 1 & 3 \\
\hline $\begin{array}{l}\text { Percentage } \\
\text { of } \\
\text { agreement= }\end{array}$ & 100 & 100 & 97.72 & 100 & 100 & 100 & 97.72 & 88.63 & 100 & 100 & 97.72 & 100 & 100 & 100 \\
\hline
\end{tabular}

